This item was submitted to Loughborough's Research Repository by the author.

Items in Figshare are protected by copyright, with all rights reserved, unless otherwise indicated.

\title{
Development of a 0.6-MV ultracompact magnetic core pulsed transformer for
} high-power applications

\section{PLEASE CITE THE PUBLISHED VERSION}

https://doi.org/10.1109/TPS.2017.2781620

PUBLISHER

(c) IEEE

\section{VERSION}

NA (Not Applicable or Unknown)

\section{LICENCE}

CC BY-NC-ND 4.0

\section{REPOSITORY RECORD}

Pecastaing, Laurent, Mark Rivaletto, Antoine Silvestre De Ferron, Romain Pecquois, and Bucur Novac. 2019. "Development of a 0.6-MV Ultracompact Magnetic Core Pulsed Transformer for High-power Applications". figshare. https://hdl.handle.net/2134/28069. 


\title{
Development of a 0.6 MV ultra-compact magnetic core pulsed transformer for high power applications
}

\author{
${ }^{1}$ Laurent Pecastaing, Senior Member, IEEE, ${ }^{1}$ Marc Rivaletto, ${ }^{1}$ Antoine De Ferron, ${ }^{2}$ Romain Pecquois \\ and ${ }^{3}$ Bucur M Novac, Senior Member, IEEE \\ ${ }^{1}$ UNIV PAU \& PAYS ADOUR, Laboratoire des Sciences de l'ingénieur appliquées à la mécanique et au génie \\ électrique - IPRA, EA4581, 64000, Pau, FRANCE \\ ${ }^{2}$ HI PULSE, Pont de Pany, FRANCE \\ ${ }^{3}$ Wolfson School of Mechanical, Electrical and Manufacturing Engineering, Loughborough University, \\ Loughborough, Leicestershire LE11 3TU, UK
}

\begin{abstract}
The generation of high-power electromagnetic waves is one of the major applications in the field of high-intensity pulsed power. The conventional structure of a pulsed power generator contains a primary energy source and a load separated by a power-amplification system. The latter performs time-compression of the slow input energy pulse and delivers a high-intensity power output to the load. Usually, either a Marx generator or a Tesla transformer is used as a power-amplifier. In the present case a system termed MOUNA (French acronym for 'Module Oscillant Utilisant une Nouvelle Architecture'), uses an innovative and very compact resonant pulsed transformer to drive a dipole antenna. The paper describes the ultra-compact multiprimary winding pulsed transformer developed in common by Université de Pau and Hi Pulse Company that can generate voltage pulses of up to $0.6 \mathrm{MV}$, with a rise time of less than $270 \mathrm{~ns}$. The transformer design has four primary windings, with two secondary windings in parallel and a Metglas ${ }^{\circledR}$ 2605SA1 amorphous iron magnetic core with an innovative bi-conic geometry used to optimize the leakage inductance. The overall unit has a weight of $6 \mathrm{~kg}$ and a volume of only 3.4 litres and the paper presents in detail its design procedure, with each of the main characteristics being separately analysed. In particular, simple but accurate analytical calculations of both the leakage inductance and the stray capacitance between the primary and secondary windings are presented and successfully compared with CST-based results. Phenomena such as the core losses and saturation induction are also analysed. The resonant power-amplifier output characteristics are experimentally studied when attached to a compact capacitive load, coupled to a capacitive voltage probe developed jointly with Loughborough University. Finally, an LTspice-based model of the power-amplifier is introduced and its predictions are compared with results obtained from a thorough experimental study.
\end{abstract}

\section{Introduction}

For the last few years, the Intentional Electro-Magnetic Interference (IEMI) has been developed as a new threat to electronic systems. The aim of the novel directed energy weapons based on High Power Microwave (HPM) technology [1][2][3][4][5] is to try to interact with today's modern increasingly complex combination of software and hardware electronics. Basically, there are two types of IEMI threats having either narrowband or wideband waveforms. Whereas the narrowband waveform threats (in the domain of a few and up to tens of $\mathrm{GHz}$ ) use vacuum technology sources, the wideband and ultra-wideband (UWB) waveform threats (in the domain of a few hundreds of $\mathrm{MHz}$ and up to a few $\mathrm{GHz}$ ) are based on high-power fast switching technologies [6][7]. Related to the wideband threats, simple short duration oscillating power systems [8] are very useful tools to investigate the susceptibility of electronic systems using unprotected wiring (Ethernet cables and/or power cords). The conventional design of such a type of directed energy weapon consists of a primary energy source and an antenna, separated by a power-amplification system that forwards the conditioned energy impulse from the source to the antenna, such as a Marx generator [9] or an air-core Tesla transformer [10]. The present arrangement however (described in [11]), uses an innovative ultra-compact $0.6 \mathrm{MV}$ resonant magnetic core transformer which allows an important volume-saving when compared with similar pulsed power generator topologies previously described in open literature. The aim of the present paper is to present in detail the development of the resonant magnetic core pulsed transformer. The design procedure, the calculations of 
leakage inductance and stray capacitances and an LTspice-based study [12] will all be discussed. Finally, experimental results are compared with software predictions.

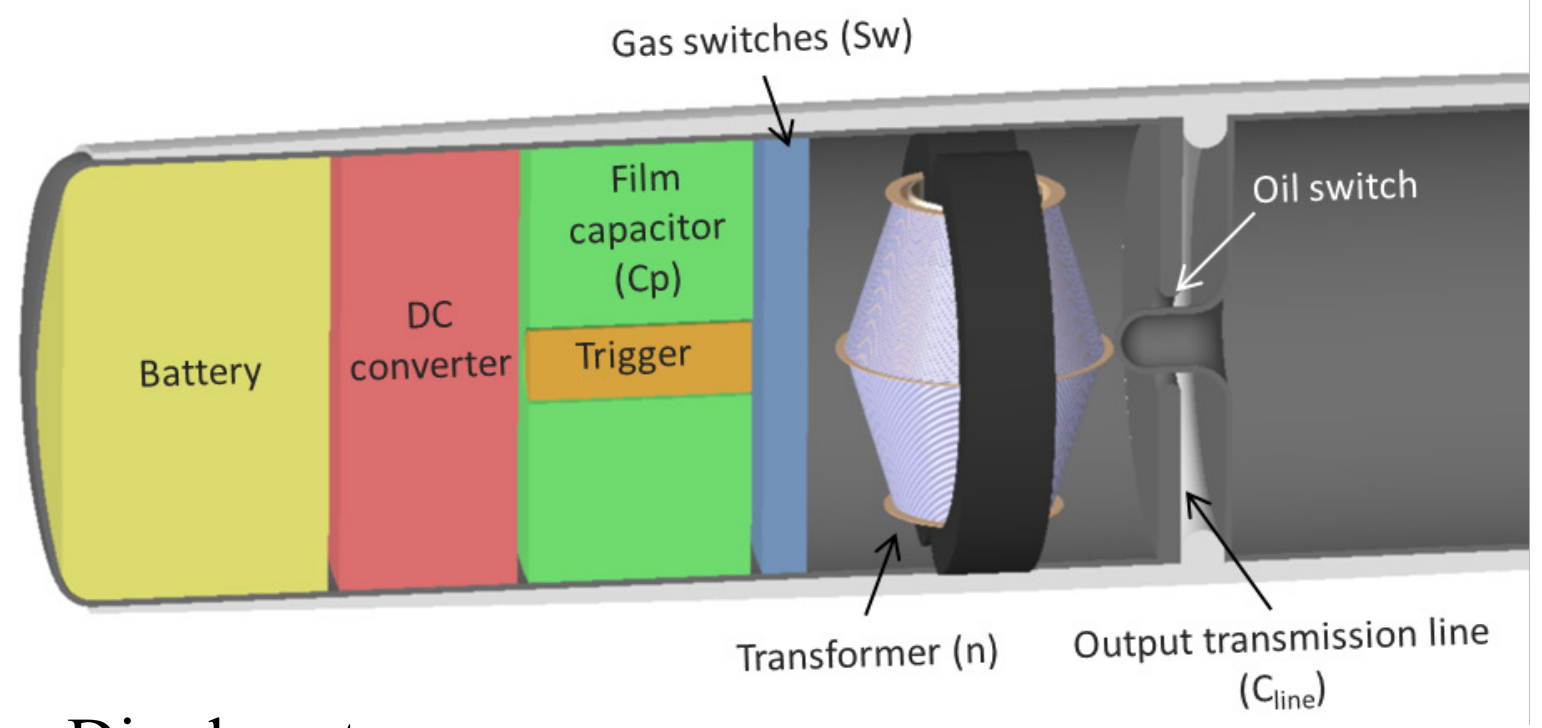

Dipole antenna

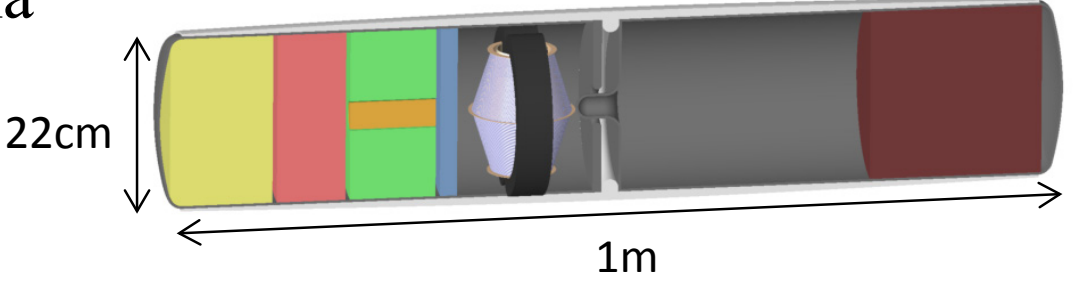

Figure 1: MOUNA electromagnetic source

Upper: arrangement of main components inside the dipole antenna; Lower: overall view of the metallic dipole antenna in which all components are integrated, with the dark volume on the far right side being an oil reservoir.

\section{MOUNA electromagnetic source and the requirements imposed on the pulsed transformer}

The study of the novel ultra-compact $0.6 \mathrm{MV}$ resonant magnetic core transformer described below was part of part of a much larger project related to the design, manufacturing and testing of an autonomous and compact electromagnetic pulse source termed MOUNA [11]. Fig. 1 presents a schematic diagram of the overall MOUNA system housed inside a dipole antenna having a length of about $1 \mathrm{~m}$, a diameter of about $22 \mathrm{~cm}$ and corresponding to a volume of about 38 litres. The MOUNA energy source is based on a magnetic core pulsed transformer powered by a battery-charged $\mathrm{HV}$ DC/DC converter charging a capacitor $\mathrm{C}_{\mathrm{p}}$ to an initial voltage $\mathrm{V}_{\mathrm{p}}$. The capacitor is mounted in the primary winding circuit discharged using a triggered closing switch $\mathrm{S}_{\mathrm{w}}$. Fig. 2 presents the equivalent electrical scheme of the MOUNA circuit, highlighting the resonant energy transfer principle. When the switch closes, the energy stored in the capacitor is transferred to an oil-filled output transmission line (having a capacitance included in the overall load equivalent capacitance $\mathrm{C}_{\mathrm{s}}$ of Fig. 2) via the high-voltage pulsed transformer, having a winding ratio $\mathrm{n}$ and a total primary winding circuit selfinductance $\mathrm{L}_{\mathrm{p}}$, which includes a leakage self-inductance $\mathrm{L}_{\sigma}$. The output transmission line has a peaking switch operated under oil and mounted at its input and a dipole antenna connected at its output. When the transmission line is crowbarred by the peaking switch, the remaining circuit is equivalent to a damped oscillator, the energy of which is radiated by the dipole antenna. 


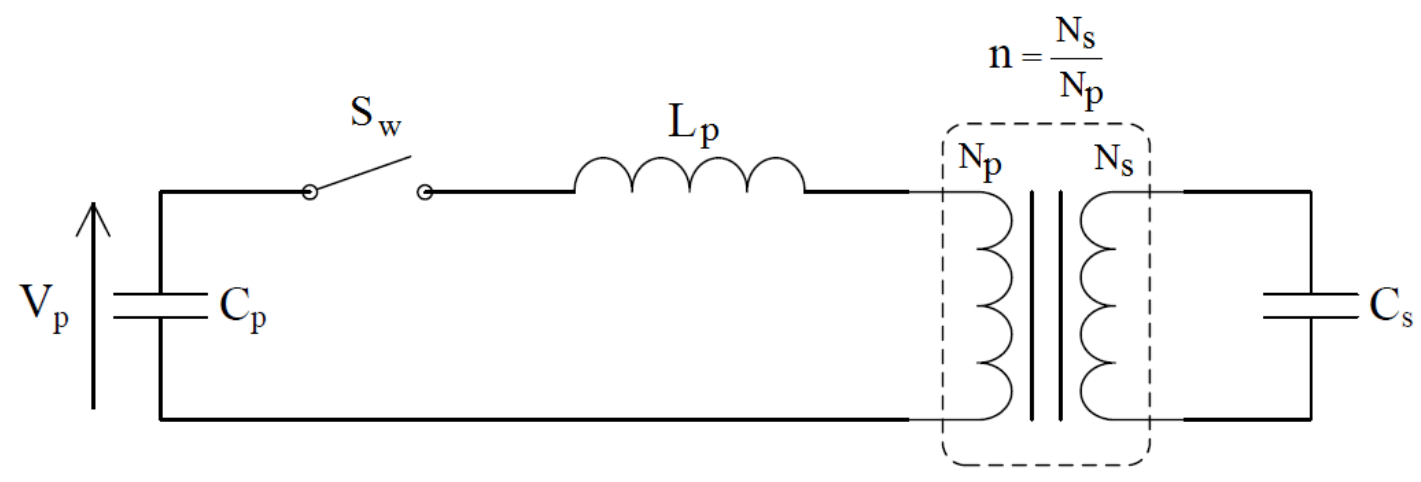

Figure 2: MOUNA simplified circuit highlighting the principle of resonant energy transfer

For a resonant transformer the transfer is optimal when[13]:

$C_{p}=n^{2} C_{s}$

with the corresponding maximum output voltage $\mathrm{V}_{\mathrm{s}}$ given by:

$V_{s}=n V_{p}$

The transformer load capacitance $C_{s}$ includes the capacitance of the transmission line $C_{\text {line, }}$, the capacitance between primary and secondary windings $C_{p s}$, the capacitance between the secondary winding and the magnetic core $\mathrm{C}_{\mathrm{sc}}$ and other stray capacitances that will be detailed later.

As the antenna includes all components, its size is fixed by the overall volume constraints of the MOUNA project. In such conditions CST Microwave Studio [14] simulations were used to obtain the optimum value of the transmission line capacitance Cline as $80 \mathrm{pF}$ [13] for which, at a $600 \mathrm{kV}$ charging voltage, the maximum amount of energy is transferred (coupled) to the dipole antenna. This essential result is actually imposing both limits and requirements to the design of the entire transformer-based pulsed power generator. The pulsed transformer is required therefore to amplify the initial voltage of $10 \mathrm{kV}$ up to $600 \mathrm{kV}$ and be capable to charge an $80 \mathrm{pF}$ capacitive load. At the same time, the transformer has to minimise its volume, but still preserve its electrical integrity under very high electric field stress.

Same type of CST simulations [11], showed that the closure time of the peaking switch has an influence on the antenna radiation gain and it was found that this time can be reduced if the time-to-peak, also termed transfer time, of the output voltage signal generated by the transformer is made shorter.

Taking into account all the results obtained during the preliminary study of the MOUNA source, it was decided that the main electrical performance required from the pulsed transformer is the generation on $\mathrm{C}_{\mathrm{s}}$ of a voltage impulse of $0.6 \mathrm{MV}$ with a transfer time less than $500 \mathrm{~ns}$. As an immediate consequence and according to Eq. 2, because the charging voltage $V_{p}$ of the primary capacitance $C_{p}$ is limited by the DC/DC converter to $10 \mathrm{kV}$, the transformer winding ratio $n$ must be 60 . If the primary winding is chosen to be a single-turn coil (i.e., $\mathrm{N}_{\mathrm{p}}=1$ ), the secondary winding will have a number of turns $\mathrm{N}_{\mathrm{s}}=\mathrm{n}$.

\section{Pulsed transformer design procedure, its geometry and the magnetic core characteristics}

The procedure to design of the transformer is detailed below. The starting point is to fulfil the required electrical parameters $V_{p}, V_{s}, C_{\text {line }}, t_{\text {peak }}$ (defined below). The need for a certain magnetic core saturation characteristic $\mathrm{B}_{\mathrm{sat}}$ and a particular magnetic core geometry are both clearly explained below. The required dimensions of the magnetic core i.e., its inner core radius $\left(\mathrm{R}_{\mathrm{in} \_ \text {core }}\right)$, cross section $(\mathrm{S})$ and height $(\mathrm{h})$ are roughly estimated. These values were used to help in choosing a particular magnetic core from the manufacturer's catalogue. Once the precise geometry of the core is thus established, including its square shape core section, the next steps are to calculate the transformer stray elements: its leakage inductance $\left(\mathrm{L}_{\sigma}\right)$ and both transformer capacitances: primary to secondary $\left(\mathrm{C}_{\mathrm{ps}}\right)$ and secondary to core $\left(\mathrm{C}_{\mathrm{sc}}\right)$. Firstly, simple techniques are established to estimate analytically these essential parameters, followed by their benchmarking against very precise, but time consuming, calculations using a state-of-the-art software package (CST). Finally, an optimization process 
is described that helps to improve the transformer characteristics that are then used with a circuit solver (LTSpice) to simulate the final electrical performance of the pulsed transformer.

The transfer time (or time-to-peak, $0 \%$ to $100 \%$ ) of the transformer output voltage can be expressed as:

$t_{\text {peak }}=\pi \sqrt{L_{p} \frac{C_{p} n^{2} C_{s}}{C_{p}+n^{2} C_{s}}}$

As easily noticed the transfer time depends on $\mathrm{L}_{\mathrm{p}}$ which includes, apart from the leakage self-inductance $\mathrm{L}_{\sigma}$, other parasitic self-inductances related to wires, capacitors, switches, connections, etc. The leakage selfinductance depends mainly on the volume between the primary and the secondary windings [16] and therefore this volume must be kept as low as possible. A conical form for the secondary winding (see Fig. 3), in contrast to the standard cylindrical winding, maintains the electric field (approximated as the ratio of voltage by radius) at a relatively constant value along the $\mathrm{z}$ axis and therefore can better accommodate the high-voltage insulation requirements. As a consequence, the volume is reduced and interestingly, as demonstrated later, the leakage inductance value is also lowered.
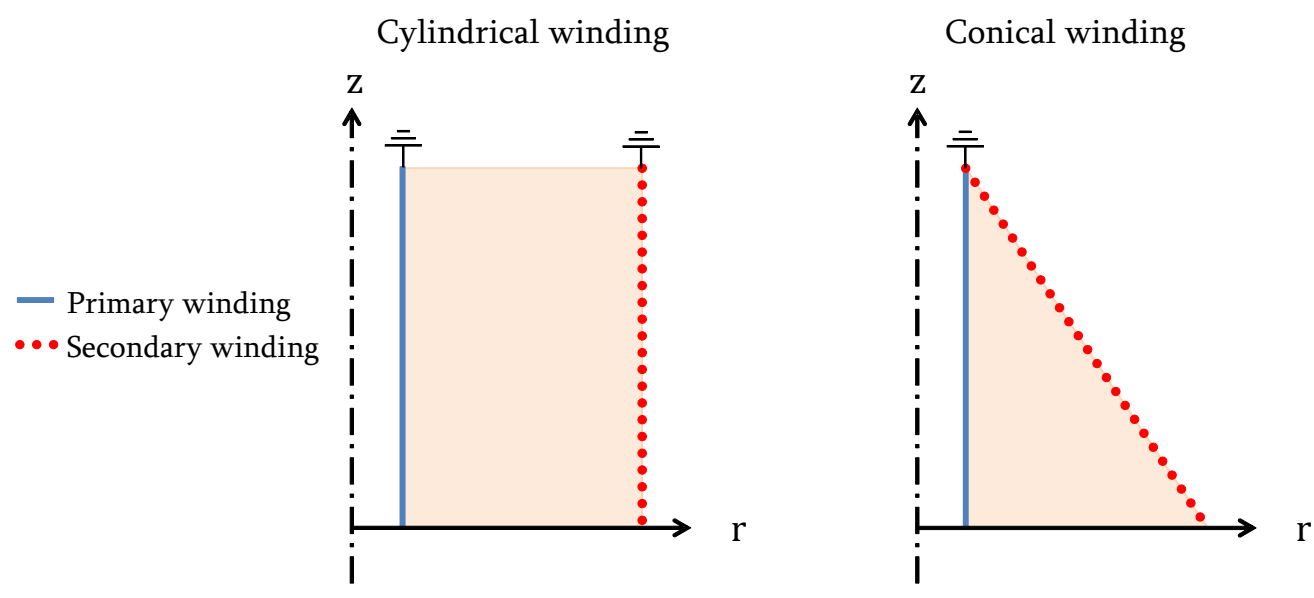

Figure 3: Winding strategies for the secondary winding

Fig. 4 shows the transformer magnetic circuit consisting of two separate D-shaped circuits designed to fit inside the $200 \mathrm{~mm}$ diameter cylindrical volume required by MOUNA. In the transformer center the magnetic core, which is made from the two D pieces touching, has an overall square cross section S. Due to mechanical requirements for inserting the windings and the bi-conical electrical insulation, each circuit is broken into two parts and the assembly is compressed by a conductive clam collar. The secondary consists of two conical windings, connected in parallel for halving the leakage inductance and although this feature results in an increased parasitic capacitance, it will be later proved that this design reduces the transfer time. 


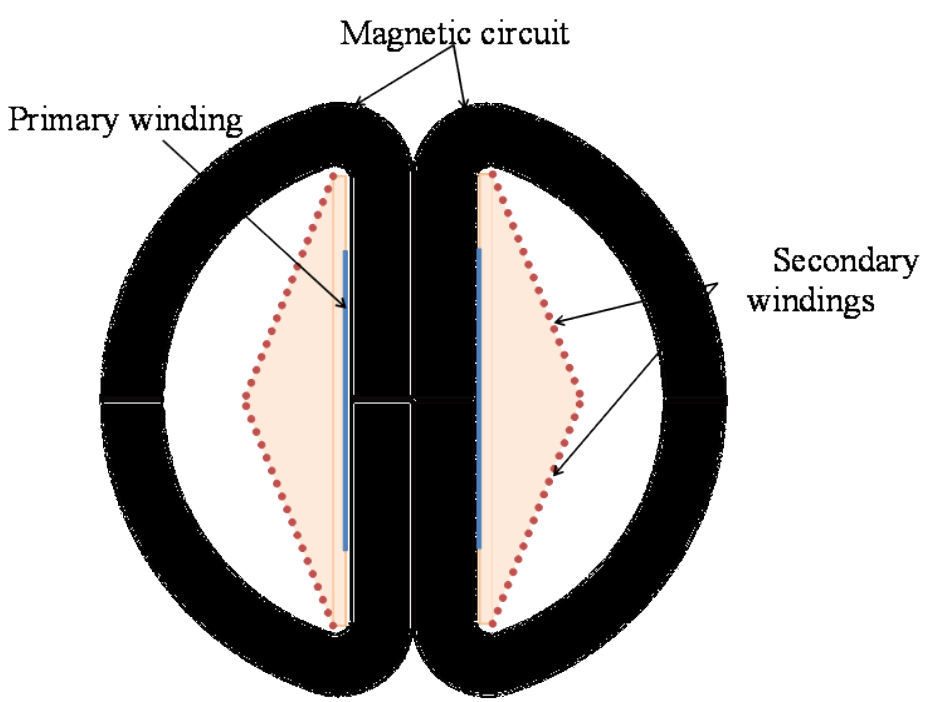

Figure 4: Sectional view of the transformer geometry

As both the transformer and the crowbar peaking switch operate under oil, tests were performed to experimentally determine the oil pulsed electrical field breakdown for conditions close to the present application. The oil chosen is a high-quality transformer oil type Mobilect 39 [17], produced by the Mobil Company, and the tests consisted of applying voltage impulses with a time-to-peak of $500 \mathrm{~ns}$ to the oil-filled peaking switch. For obtaining the required performance at $0.6 \mathrm{MV}$, a gap distance of about $4 \mathrm{~mm}$ was found to be necessary. For conditions inside the transformer, the electric field $\mathrm{F}_{\mathrm{BD}}$ (in $\mathrm{kV} / \mathrm{cm}$ ) for which there is a $50 \%$ probability of electric breakdown, depends on the area under electric stress A (in $\mathrm{cm}^{2}$ ) and the effective stress time $t_{\text {eff }}$ (in $\left.\mu \mathrm{s}\right)$ by the expression [18]:

$F_{B D}=480 t_{\text {eff }} f^{-\frac{1}{3}} A^{-0.073}$

valid for uniform field configurations. For the specific working conditions the $\mathrm{F}_{\mathrm{BD}}$ is estimated around $1000 \mathrm{kV} / \mathrm{cm}$, a value very close to $1100 \mathrm{kV} / \mathrm{cm}$ determined experimentally [19].

The magnetic circuit is made of Metglas ${ }^{\circledR}$ 2605SA1 [20]. The advantages of using this material are: low losses, a good behaviour at high frequency and a large value for the saturation induction $\mathrm{B}_{\text {sat }}$ of $1.56 \mathrm{~T}$. This material, with characteristics provided in [15], is commonly used in power transformers and coils operated at high frequency. The magnetic circuit must be designed with a cross-section large enough not to allow saturation during the energy transfer. In the case of resonant transfer, the variation of the magnetic induction $\Delta \mathrm{B}=\mathrm{B}_{\text {sat }}$ during $\mathrm{t}_{\text {peak }}=\mathrm{T} / 2$ is related to the integral of the output voltage by the following equation:

$\int_{0}^{\frac{T}{2}} V_{S}(t) d t=N_{S} \cdot \Delta B \cdot S$

where $\mathrm{T}$ is the period and $f=1 / \mathrm{T}$ is the corresponding frequency of the output voltage impulse. The cross section can be straightforwardly estimated from:

$\int_{0}^{\frac{T}{2}} \frac{V_{\text {Smax }}}{2}\left[1-\cos \left(\frac{2 \pi}{T} t\right)\right] d t=\frac{V_{\text {Smax }} T}{4}$

For $\mathrm{V}_{\mathrm{Smax}}=600 \mathrm{kV}, \mathrm{T} / 2=500 \mathrm{~ns}, \mathrm{~N}_{\mathrm{S}}=60$ and $\Delta \mathrm{B}=1.56 \mathrm{~T}$, the cross section $\mathrm{S}$ is obtained as:

$S=\frac{V_{\text {Smax }} T}{4 N_{S} \Delta B} \approx 1600 \mathrm{~mm}^{2}$

As a consequence, as the central magnetic material has a square cross section, the side of the square is $\mathrm{c}=40 \mathrm{~mm}$ and therefore each $\mathrm{D}$ shaped piece in Fig. 4 has a thickness $\mathrm{c} / 2$. 
The circular single-turn primary winding, made from a $0.5 \mathrm{~mm}$ thick copper foil, has to be mounted as close as possible to the magnetic circuit. The minimum inner diameter $D_{\text {in_prim }}$ of the primary winding can be calculated as:

$D_{\text {in_prim }}=c \sqrt{2}+2 e$

where $e$ is the thickness of the cylindrical primary winding dielectric mandrel. The dielectric material used to mechanically hold the winding and provide insulation to the magnetic core is made of Polyoxymethylene (POM). The DC dielectric strength of POM is in excess of $20 \mathrm{kV} / \mathrm{mm}$ and therefore a $1 \mathrm{~mm}$ thickness is sufficient but, to ensure sufficient mechanical strength, its thickness has been chosen $2 \mathrm{~mm}$. In these conditions and using Eq. (8) $D_{\text {in_prim }}$ is about $60.5 \mathrm{~mm}$.

Each secondary winding is wound on a conical shaped mandrel. The dielectric strength of the oil is close to the dielectric strength of the material used to manufacture the mandrel and the electric field can be considered as homogeneous. In such a case the best solution is to position the last turn of the secondary winding (which is raised at the highest voltage) at an equal distance from both the magnetic circuit and the primary winding.

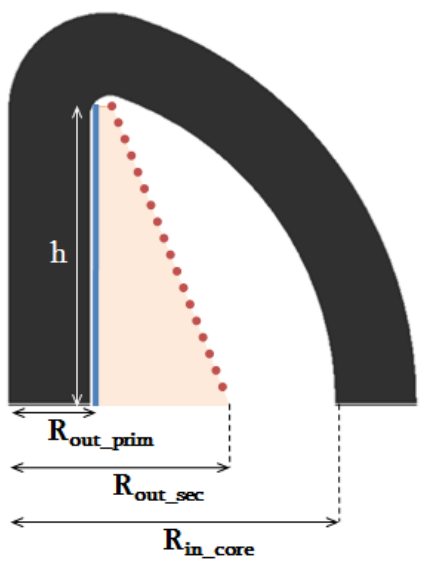

Figure 5: Definition of the main transformer dimensions

To meet this requirement and in reference to Fig. 5, for $R_{\text {in_core }}=80 \mathrm{~mm}$ and $R_{\text {out } \_ \text {prim }}=31 \mathrm{~mm}$, it is necessary that:

$R_{\text {out_sec }}=\frac{R_{\text {in_core }}+R_{\text {out_prim }}}{2} \approx 55.5 \mathrm{~mm}$

The height $\mathrm{h}$ in Fig. 5, valid for both the primary and the secondary winding, can be estimated as:

$h \approx \sqrt{R_{\text {int_core }}^{2}-R_{\text {out_prim }}^{2}} \approx 74 \mathrm{~mm}$

Once the conical mandrel is defined, in order to wind the 60 turns for each of the two parallel-mounted secondary windings, it is necessary the pitch $\mathrm{p}$ to be less than a value estimated as:

$p=\frac{\sqrt{h^{2}+\left(R_{\text {out_sec }}-R_{\text {out_prim }}\right)^{2}}}{n} \approx 1.3 \mathrm{~mm}$

The selected wire is a single strand of copper with an insulating sheath made of Teflon. Its outer diameter is $1.25 \mathrm{~mm}$ and the diameter of the conductor of $0.65 \mathrm{~mm}$ (AWG 22). The main advantages of a Teflon sheath are very good dielectric properties but even more importantly its good resistance to mineral oil attack. As the transformer is operated at a frequency $f$ of about $1 \mathrm{MHz}$, the skin effect plays a significant role, but these losses are negligible when compared with the magnetic core losses and therefore the use of Litz wires would not bring an improvement. The resultant secondary winding design is presented in Fig. 6. 


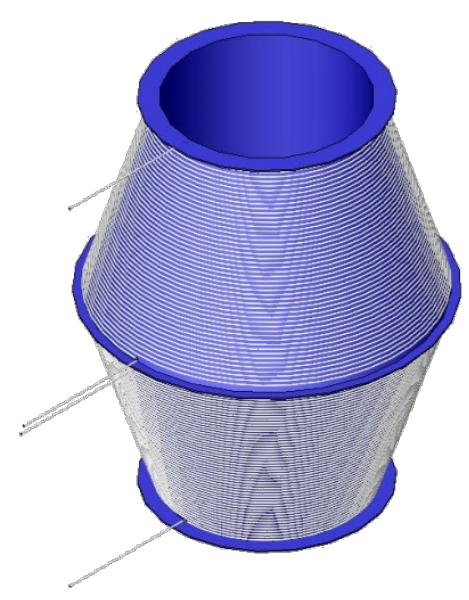

Figure 6: 3D drawing of the two, parallel-mounted, secondary windings

The average magnetic path $\mathrm{L}_{\mathrm{C}}$ of the two D-shaped circuits can be calculated as:

$L_{c}=2\left(R_{\text {out_core }}-\frac{c}{4}\right) \tan ^{-1}\left(\frac{\sqrt{\left(R_{\text {out_core }}-\frac{c}{4}\right)^{2}-\left(\frac{c}{4}\right)^{2}}}{c / 4}\right)+2 \sqrt{\left(R_{\text {out_core }}-\frac{c}{4}\right)^{2}-\left(\frac{c}{4}\right)^{2}}$

In Eq.(12) $R_{\text {out core }}=100 \mathrm{~mm}$ is the outer radius of the magnetic core and the resultant Lc is estimated as $442 \mathrm{~mm}$. The magnetic core mass $\mathrm{M}_{\mathrm{C}}$ can be also estimated as:

$M_{c}=L_{c} \cdot S \cdot \rho$

and, for the magnetic material density $\rho=7.18 \mathrm{~g} / \mathrm{cm}^{3}$, the results is $\mathrm{M}_{\mathrm{C}} \approx 5.1 \mathrm{~kg}$.

To have an idea of the energy efficiency of the magnetic core transformer, we use the Steinmetz empirical law [21] for an accurate estimation of the magnetic core power density losses $P_{w}$ at a sinusoidal resonant frequency $f$ (defined above) as:

$P_{w}=k f^{\alpha} \hat{B}^{\beta}$

where $\hat{B}=B_{\text {sat. }}$. Using the values for the coefficients as provided in [22]: $\mathrm{k}=6, \alpha=1.51$ and $\beta=1.74$, the result is obtained as $\mathrm{P}_{\mathrm{w}} \approx 445 \mathrm{~kW} / \mathrm{kg}$. During a pulse, the energy $E_{j}$ lost in the magnetic core can be calculated as:

$E_{j}=P_{w} \cdot t_{\text {peak }} \cdot M_{c}$

with the result, $E_{\tilde{j}} \approx 1 \mathrm{~J}$, representing only $2.5 \%$ of the total initial stored energy in the primary winding capacitance.

\section{Leakage inductance calculation}

As already indicated, the transformer total leakage inductance $L_{\sigma}$ is one of the parameters which influences the rise time of the transformer and therefore it is essential to minimize its value. For convenience, an analytical calculation of leakage inductance gives in most cases an acceptable estimate to be used in the design of transformers. For one of the two identical and parallel-mounted secondary windings of the transformer, the leakage inductance $l_{\sigma}$ is related to the total energy $W_{\text {magnetic }}$ stored by an imperfect flux coupling in the nonmagnetic regions between primary and secondary windings. This energy can be estimated as [23]:

$W_{\text {magnetic }}=\frac{1}{2} l_{\sigma} I_{p}{ }^{2}$

where $I_{p}$ is the primary current. For the present design, both the primary and the secondary windings represent only thin layers, occupying small volumes as compared with the volume between primary and secondary windings [24]. In such conditions it is reasonable to consider a constant magnetic field $H$ generated in the space between the two windings [16]. With this assumption, the total energy stored is calculated as:

$W_{\text {magnetic }}=\frac{\mu_{0}|H|^{2}}{2} \mathrm{Vol}=\mu_{0} \frac{\left(\frac{N_{p} I_{p}}{h}\right)^{2}}{2} \mathrm{Vol}$ 
for which the corresponding leakage self-inductance can be estimated as:

$$
l_{\sigma}=\frac{\mu_{0} N_{p}{ }^{2}}{h^{2}} \mathrm{Vol}
$$

where $\mathrm{Vol}$ is the dielectric volume between the coils, measured as $290 \mathrm{~cm}^{3}$. For the dimensions calculated previously and $\mathrm{N}_{\mathrm{p}}=1$, the estimated leakage self-inductance is about $67 \mathrm{nH}$, in good agreement with measurements performed with a HIOKI IM3536 LCR bridge at $1 \mathrm{MHz}$ providing values between $64 \mathrm{nH}$ and $66 \mathrm{nH}$. We note that the leakage inductance value for a cylindrical winding strategy for this transformer (Fig. 3.a.) is about $113 \mathrm{nH}$ making obvious that the conical winding strategy is advantageous, allowing a $41 \%$ reduction of this unwanted parameter. As the transformer has two secondary windings mounted in parallel, its total leakage self-inductance was approximated as $\mathrm{L}_{\sigma} \approx 33 \mathrm{nH}$. Estimates were also obtained for the selfinductance of the primary capacitor as about $67 \mathrm{nH}$ and for all electrical connections including the closing switch as about $50 \mathrm{nH}$, allowing the total self-inductance of the primary winding circuit $\mathrm{L}_{\mathrm{p}}$ to be estimated as $150 \mathrm{nH}$.

A study made using CST EM Studio [25] confirmed all these simple estimates. The results in Fig. 7 show that, apart from a slight field enhancement just visible near the primary windings, the intensity of the magnetic field is indeed constant in the material between the primary and secondary windings, as assumed above (with a value around $160 \mathrm{kA} / \mathrm{m}$ ). In addition, CST EM Studio evaluates the total magnetic energy stored in this space at about $9 \mathrm{~J}$, a value that validates the above estimate of the total leakage inductance $\mathrm{L} \sigma$.

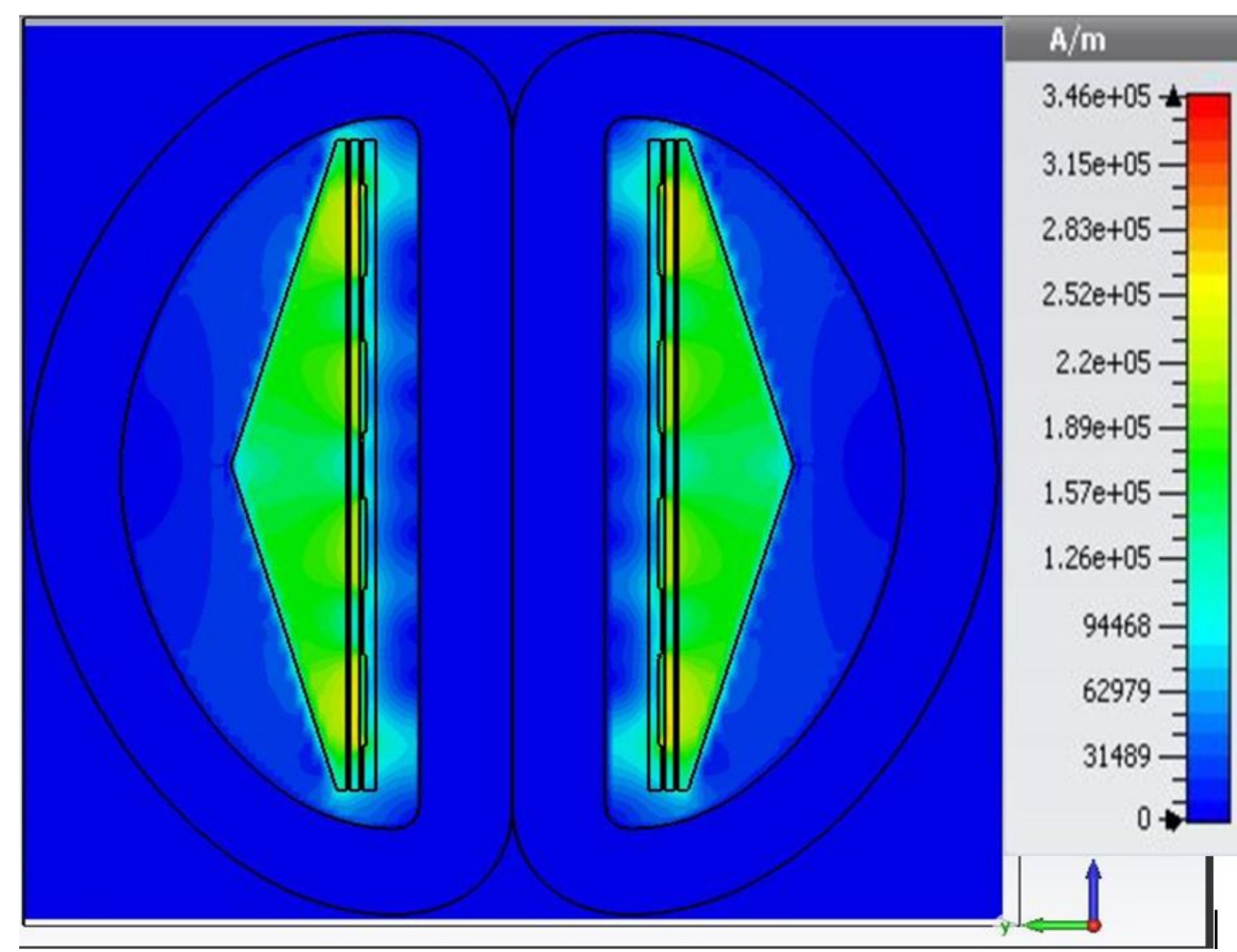

Figure 7: CST EM Studio simulation of transformer magnetic field intensity

\section{Capacitances calculation}

In high frequency transformers, there are four different types of capacitance [26]: capacitance between the turns in a winding, capacitance between the layers of a winding, capacitance between windings and stray capacitance between the windings and the magnetic core. In the present case the first two can be neglected in respect to the last two. In what follows the most important capacitance, that one between the primary and secondary winding will be evaluated, followed by an estimate of the stray capacitance of the secondary winding to core. 
In analogy with the technique used to estimate the leakage inductance, the primary-secondary capacitance $C_{p s}$ will be calculated using the electric energy $W_{\text {electric }}$ stored between the two windings:

$W_{\text {electric }}=\frac{1}{2} C_{p s} n^{2} V_{p}^{2}=\frac{1}{2} \varepsilon_{0} \varepsilon_{r} \int_{V o l} \vec{E}^{2} d v$

where $\varepsilon_{0}$ is the permittivity of free space, $\varepsilon_{\mathrm{r}}=3.7$ the relative permittivity of the POM and $\vec{E}$ is the electric field vector generated between windings.

The primary coil is mounted very close to the beginning of the secondary coil, so that $\mathrm{R}_{\text {out prim }} \approx \mathrm{R}_{\text {in_sec. The }}$ distance $\mathrm{D}_{\mathrm{ps}}$ between the two coils and the electrical potential between them, they both vary linearly with axial distance $\mathrm{z}$ :

$D_{p s}(z)=\frac{R_{\text {out_sec }}-R_{\text {out_prim }}}{h} z$

$V_{p s}(z)=\frac{n}{h} V_{p} z$

As a consequence the electric field is practically constant:

$E_{p s}(z)=\frac{n V_{p}}{R_{\text {out_sec }}-R_{\text {out_prim }}}=E_{\text {max }}$

In these conditions the calculation is straightforward:

$\frac{1}{2} n^{2} V_{p}{ }^{2} C_{p s}=\frac{1}{2} \varepsilon_{0} \varepsilon_{r} \int_{R_{\text {out_prim }}}^{R_{\text {out_sec }}} r d r \int_{0}^{2 \pi} d \theta \int_{0}^{h} E_{p s}{ }^{2}(z) d z$
$C_{p s}=\frac{\pi \varepsilon_{0} \varepsilon_{r} h\left(R_{\text {out_sec }}+R_{\text {out_prim }}\right)}{R_{\text {out_sec }}-R_{\text {out_prim }}} \approx 30 p F$

This value corresponds to only one of the two identical secondary windings. As the two secondary windings are mounted in parallel, the transformer primary to secondary capacitance is double.

A CST EM Studio simulation of the transformer provided for one winding an admittance of $195 \mu \mathrm{S}$ at $1 \mathrm{MHz}$, which corresponds to $31 \mathrm{pF}$, in excellent agreement with the simple analytical estimate of Eq. (24).

The stray capacitance $C_{s c}$ between the secondary winding and the external core can also be analytically estimated. In order to simplify the calculus of capacitance in cylindrical coordinates, the two surfaces of the capacitor $C_{S C}$ are chosen somehow arbitrary as being segments of a semicircle of angle $\alpha \approx 90^{\circ}$ (as in Fig. 8). Therefore the distance $D_{s c}$ and the voltage between the secondary winding and the core $V_{s c}$ are calculated as:

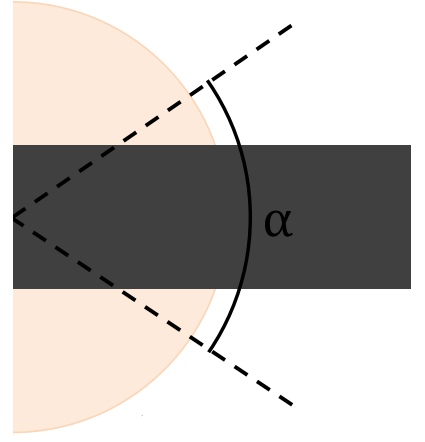

Figure 8: Upper view of one-half of the transformer. The gray area represents the magnetic core, while the semicircle represents the secondary winding. For simplicity of calculus, to obtain a rough estimate of the capacitance between the secondary winding and the magnetic core (C) the surface area of the capacitor 'plates' is approximated by a segment of the semicircle having an angle $\alpha \approx \pi / 2$ 
$D_{s c}(z) \approx \sqrt{R_{\text {in_core }}{ }^{2}-(z-h)^{2}}-\frac{R_{\text {out_sec }}-R_{\text {out_prim }}}{h} z-R_{\text {out_prim }}$

$V_{s c}(z)=\frac{n}{h} V_{p} z$

Using (25) and (26), it is easy to determine the axial variation of the electric field:

$E_{S C}(z) \approx \frac{\frac{n}{h} V_{p} z}{\sqrt{R_{\text {in_core }}{ }^{2}-(z-h)^{2}}-\frac{R_{\text {out_sec }}-R_{\text {out_prim }}}{h} z-R_{\text {out_prim }}}$

In these conditions, $\mathrm{C}_{\mathrm{sc}}$ is obtained by numerically solving the equation:

$C_{s c}=\frac{\varepsilon_{0} \varepsilon_{r 1} \int_{R_{\text {out_sec }}}^{R_{\text {in_core }}} r d r \int_{0}^{\alpha} d \theta \int_{0}^{h} E_{s c}{ }^{2}(z) d z}{n^{2} V_{p}^{2}} \approx 6 p F$

Note that in Eq.(28) $\varepsilon_{r 1}=2.25$ is the relative permittivity of the oil in which the transformer is immersed. As above, because the transformer is composed of two secondary windings in parallel, the total secondary-core capacitance is multiplied by two. The same CST Microwave Studio simulation provided a value of $6.5 \mathrm{pF}$, again in excellent agreement with the simple estimate.

The above calculations highlight the fact that the stray capacitances cannot be neglected in respect to $\mathrm{C}_{\text {line, }}$ and this obviously affects the energy transfer efficiency. There are also other stray capacitances between:

- the secondary winding and the structure in which the transformer is enclosed (the antenna strand)

- the secondary winding and the spark gaps of the primary winding

- the secondary winding and the output spark gap

- the two secondary windings

but unfortunately these cannot be estimated by simple analytical calculations. Using CST modelling however, these were evaluated at a total of about $50 \mathrm{pF}$.

All the above analysis shows that the total capacitive output load of the transformer has a value of:

$C_{s}=C_{\text {line }}+2 C_{p s}+2 C_{s c}+50 p F \approx 200 p F$

\section{Design optimization and practical realization}

Based on the calculated value for $\mathrm{C}_{\mathrm{s}}$ and the requirement for an optimal resonant transfer (Eq.1), the value for the corresponding primary capacitance $\mathrm{C}_{\mathrm{p}}=\mathrm{n}^{2} \mathrm{C}_{\mathrm{s}}$ is about $720 \mathrm{nF}$. This value is too large because it will increase the transformer transfer time (time to peak, Eq.3) to about $725 \mathrm{~ns}$, which in turn will induce core saturation during the rise time of the input voltage. Two solutions are possible:

increase the cross-section of the magnetic circuit

decrease the self-inductance of the primary circuit so that the transfer time remains less than $500 \mathrm{~ns}$.

Increasing the magnetic circuit will result in an increase of transformer's mass and a decrease in the volume available for the windings, while the isolation constraints and the stray capacitances will also increase. The solution therefore consists in reducing the transfer time by decreasing the primary self-inductance using several windings mounted in parallel. In case of a number X of parallel mounted primary circuits, the time-topeak and the rise time are:

$t_{\text {peak }}(X)=\pi \sqrt{\left(\frac{L_{p}-L_{\sigma}}{X}+L_{\sigma}\right) \cdot \frac{C_{p} n^{2} C_{s}}{C_{p}+n^{2} C_{s}}}$

$t_{\text {rise }}(X)=0.295 \times 2 \pi \sqrt{\left(\frac{L_{p}-L_{\sigma}}{X}+L_{\sigma}\right) \cdot \frac{C_{p} n^{2} C_{s}}{C_{p}+n^{2} C_{s}}}$

and Fig. 9 presents the dependence of these time characteristics on the number of parallel-mounted primary windings. This solution brings as a bonus the advantage of reducing the current switched by each synchronized 
primary spark gap [15], thus enabling a higher pulse repetition frequency (PRF) operation to be envisaged. The total current flowing in the primary circuit can be determined from:

$$
I_{\max }(X)=\sqrt{\frac{\frac{C_{p} n^{2} C_{s}}{C_{p}+n^{2} C_{s}}}{\left(\frac{L_{p}-L_{\sigma}}{X}+L_{\sigma}\right)}} V_{p}
$$

while Fig. 10 shows the variation of both this current and of the current in each winding as a function of the number of windings.

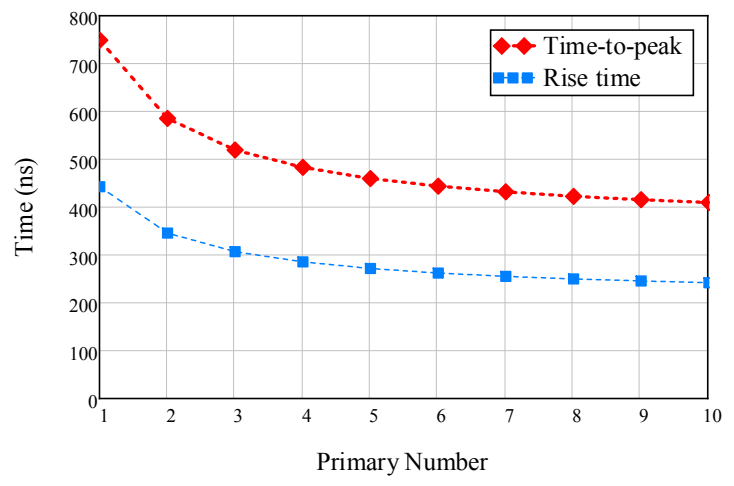

Figure 7: Variation of the time to peak and of the rise time with the number of primary windings

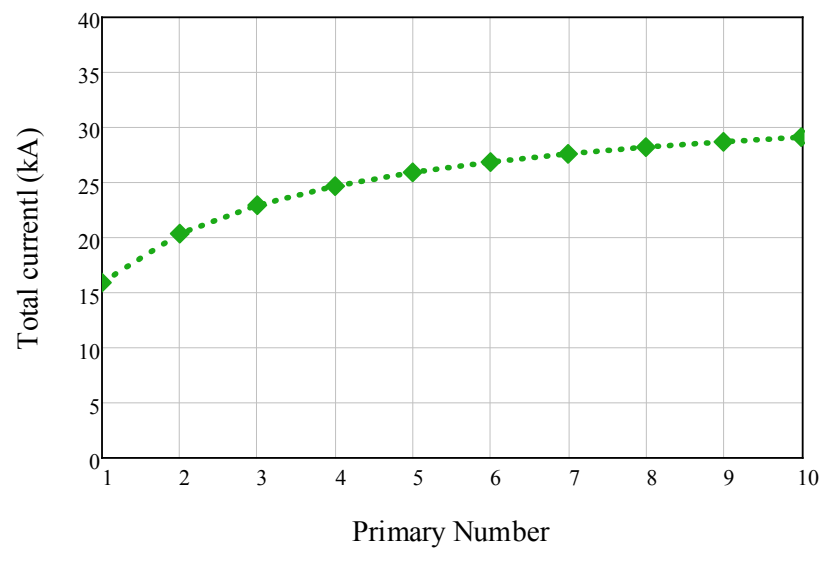

(a)

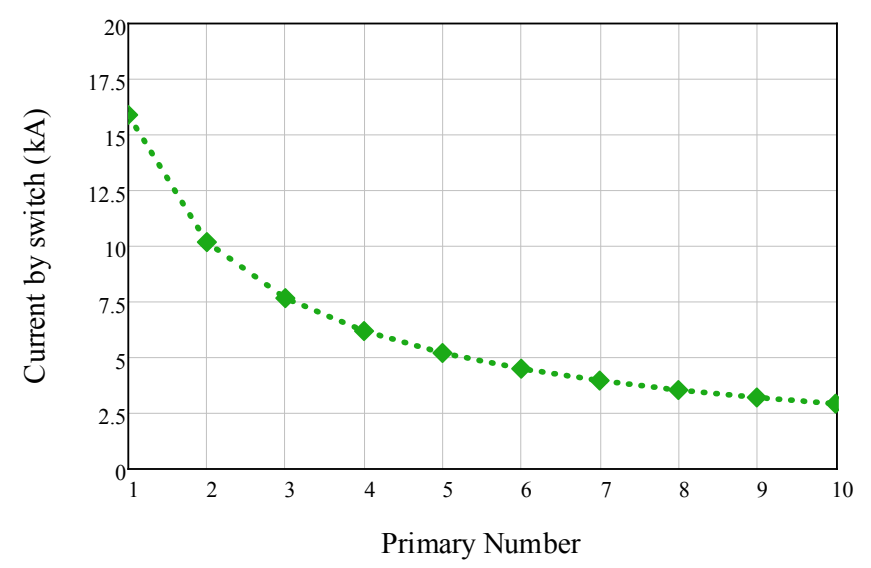

(b)

Figure 80: Variation with the number of primary windings of the: a) total primary current; b) current in each winding

The only drawback of operating X parallel circuits is the need for synchronization between the X spark-gaps. A compromise has to be found between the difficulty of mechanical realization, the current switched by each spark gap and the time-to-peak of the transformer output voltage. A reasonable choice is to have four parallel primary circuits that allows reducing the overall self-inductance of the primary circuit $\left(\mathrm{L}_{\mathrm{p}}\right)$ to $62 \mathrm{nH}$ and, as required, brings the theoretical time-to-peak to 469 ns i.e., less than the required 500 ns. A small-size Marx generator is used to synchronize the four switches [15]. At the same time, this design limits the current switched by each primary spark gap to only $6.2 \mathrm{kA}$ and thus reduces the erosion of the electrodes of the sparkgaps, allowing a higher PRF operation of the overall MOUNA system.

Unfortunately, for practical reasons related to component availability, only capacitors having a capacitance of $200 \mathrm{nF}$, a stray self-inductance of $64 \mathrm{nH}$ and capable of delivering a current of about $10 \mathrm{kA}$ were available to be used as power sources in each winding circuit. Because of this the total primary capacitance is raised to $800 \mathrm{nF}$ i.e., larger than the $720 \mathrm{nF}$ requested by Eq. (1) and such conditions the efficiency of the energy 
transfer is slightly reduced but the higher capacitance allows the generation of a larger output voltage. The time-to-peak and the rise time are $482 \mathrm{~ns}$ and $285 \mathrm{~ns}$ respectively, while the maximum primary current is $25 \mathrm{kA}$.

The single-turn primary windings loops are each made from a $0.5 \mathrm{~mm}$ thick, $20 \mathrm{~mm}$ wide copper sheet (Fig. 11(a)). For optimizing the magnetic coupling, it immediately follows that the dimensions of the singleturn should be as close to the magnetic core as allowed by the required insulating properties of the mandrel. A POM support is used both as a mandrel and as a primary winding-magnetic circuit insulator (Fig. 11(b)) and transformer Nomex ${ }^{\circledR}$ paper is used to insulate the individual windings.

To conclude, the theoretical analysis of the resonant transformer and the optimization procedure provides the following final design characteristics as:

- Four single-turn, parallel-mounted primary windings

- Two parallel-mounted secondary windings each having sixty turns

- Total primary capacitance: $800 \mathrm{nF}$ (four parallel-mounted primary capacitors each of $200 \mathrm{nF}$ )

- Total secondary capacitance: $200 \mathrm{pF}$

- Output voltage rise time: $285 \mathrm{~ns}$

- Output voltage time-to-peak: 482 ns (less than 500 ns required to avoid saturation)

- Total primary current: $25 \mathrm{kA}$

- Total secondary current: 417 A

Fig. 12 shows the final 3-D CAD drawings and Fig. 13 presents a photo of the assembled magnetic core pulsed transformer.

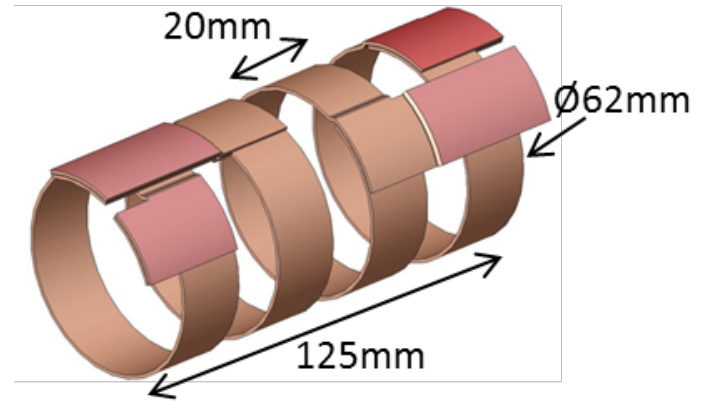

(a)

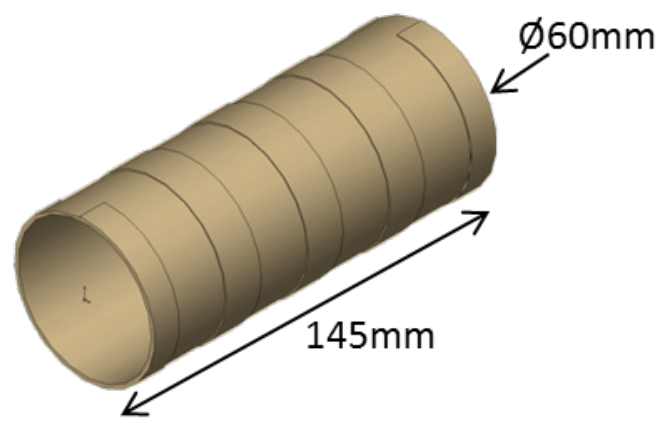

(b)

Figure 91: 3-D CAD views of (a) the four single-turn primary windings and (b) their POM mandrel 


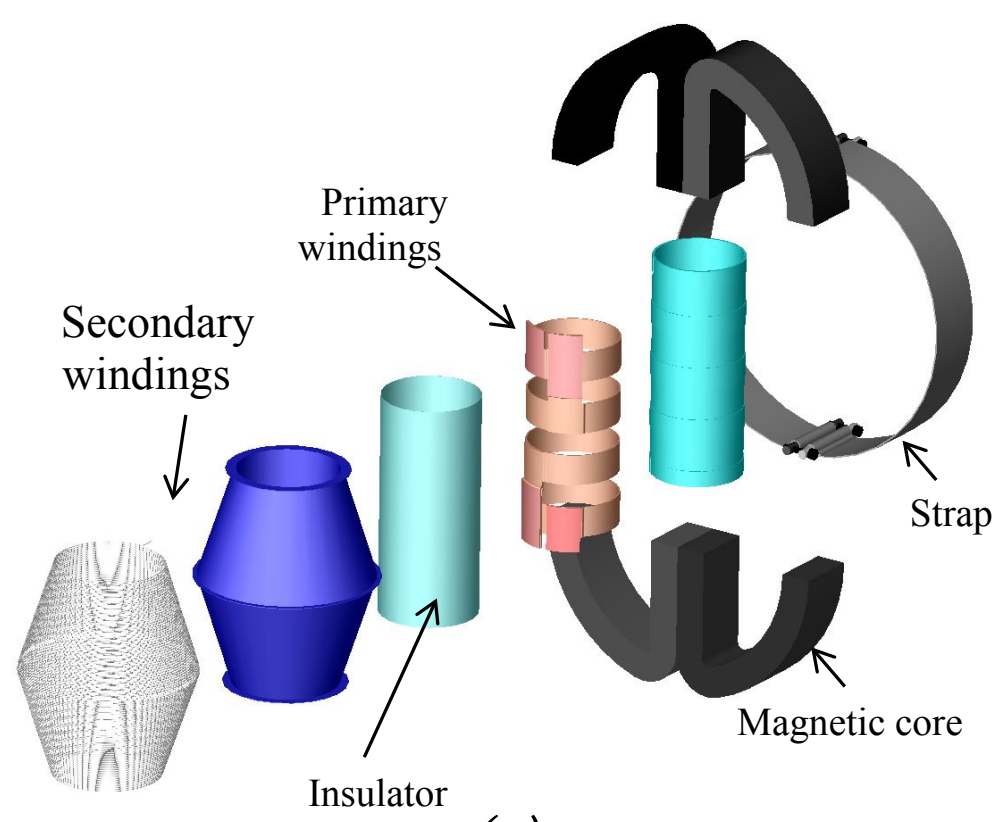

(a)

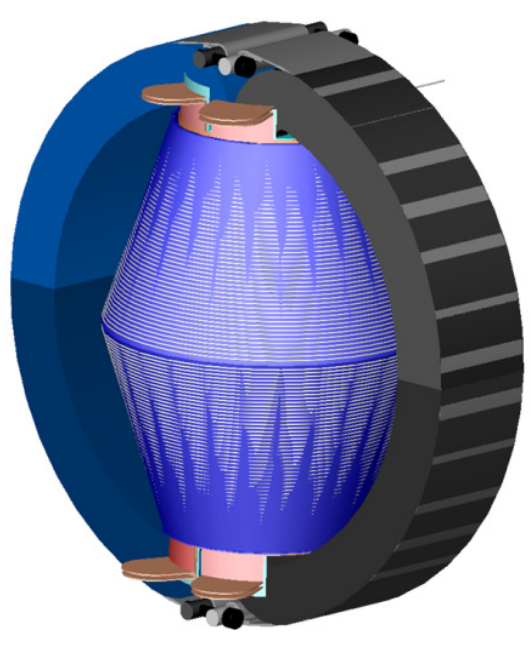

(b)

Figure 102: Final 3-D CAD design: (a) transformer exploded; (b) overall view

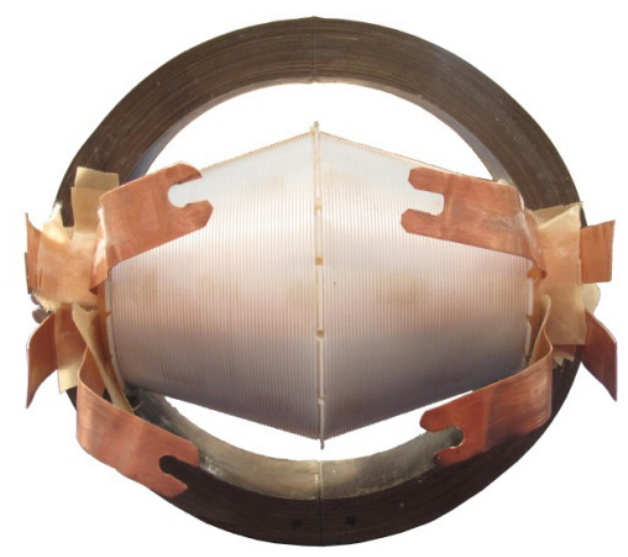

Figure 113: Picture of the completed resonant magnetic core pulsed transformer

\section{LTspice modeling}

The numerical simulation of the resonant pulsed transformer was carried out using the LTspice free software (Fig. 14), having as load a capacitor simulating the antenna, with a specially developed voltage probe [27] mounted in parallel.

The resistance of one secondary winding is about $0.85 \Omega$ for a DC current, but raises to $2.33 \Omega$ for a pulsed current injected at the transformer's resonant frequency. This last value, divided by 2 to take into account the parallel coupling of the two secondary windings, was used in numerical simulations. The results show the resistance lowers the peak voltage value by only $0.05 \%$. It is therefore reasonable to be neglected from the electrical equivalent circuit.

The model for the hysteresis cycle of the transformer core magnetic material is adopted from [28]. The magnetic model is defining the hysteresis cycle of the material using only three parameters, $\mathrm{Hc}, \mathrm{Br}$ and $\mathrm{B}_{\text {sat }}$, which respectively represent the coercive magnetic field, the remanent and the saturation magnetic flux 
density. For the Metglas ${ }^{\circledR} 2605 \mathrm{SA} 1$ the values are: $\mathrm{Hc}=4 \mathrm{~A} / \mathrm{m}, \mathrm{B}_{\mathrm{r}}=1.2 \mathrm{~T}$ and $\mathrm{B}_{\text {sat }}=1.56 \mathrm{~T}$ and the theoretical hysteresis cycle thus obtained is very close to the real curve obtained from the manufacturer (Fig. 15). Fig. 16 presents theoretical predictions: the transformer output peak is predicted to be $0.6 \mathrm{MV}$ with a rise time of $268 \mathrm{~ns}$ with the core magnetic induction reaching the saturation value just before the end of the resonant transfer. Therefore, this unwanted phenomenon has a small influence on the amplitude of the output voltage.

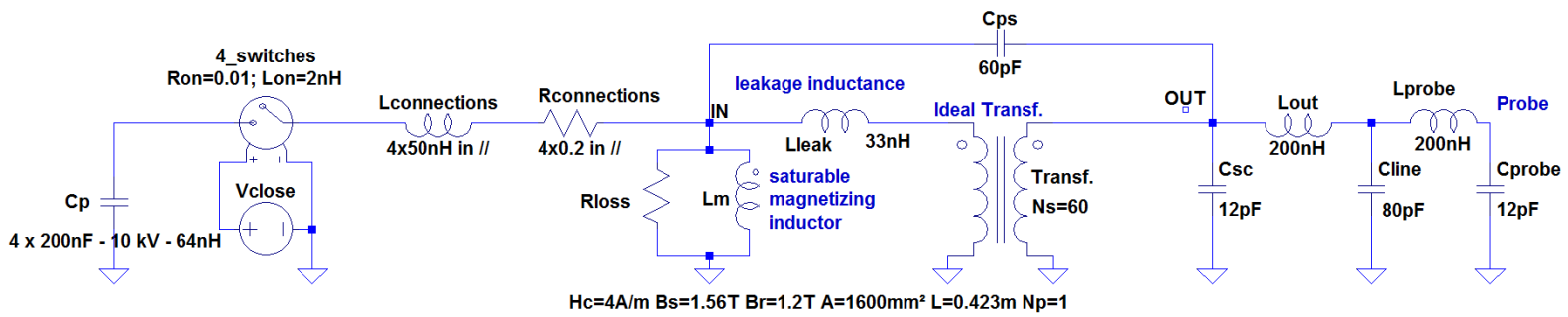

Figure 124: LTspice pulse generator simulation scheme

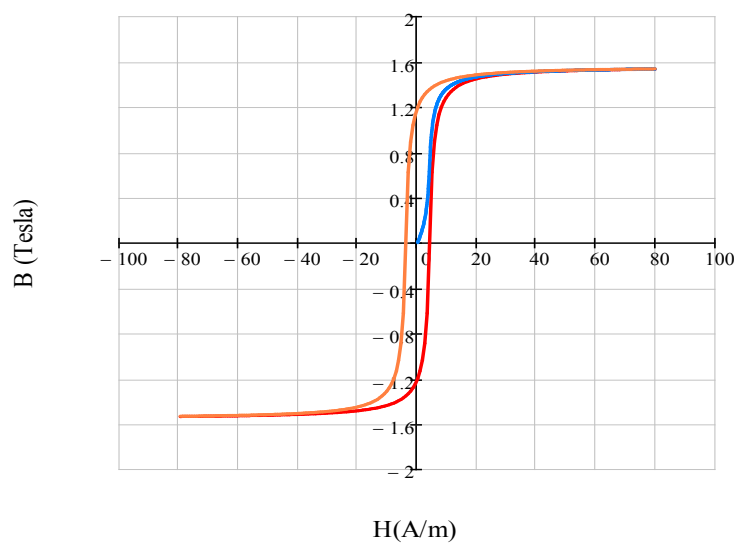

Figure 135: Hysteresis cycle for Metglas ${ }^{\circledR} 2605 \mathrm{SA} 1$

\section{Experimental results}

The transformer was tested having the same ultra-compact arrangement as when mounted inside the dipole antenna, with a polymer skeleton holding the various elements together (Fig. 17). The term 'ultra-compact arrangement' is for the fact that components are coupled with the shortest possible connections. The pulsed transformer based generator was tested in a steel tank filled with oil (Mobilect ${ }^{\mathrm{TM}}$ 39) and degassed under vacuum. The antenna is simulated by a capacitive load of $80 \mathrm{pF}$ and the measurement of the output voltage is carried out using a homemade fast 0.6 MV voltage probe described in [27]. The electrical circuit and the overall experimental arrangement are both shown in Fig. 18.

One of the challenges of the MOUNA project is the generation of signals of short duration (500 ns) and very high voltage $(0.6 \mathrm{MV})$ in a very limited volume (less than 4 litres). As the tests described here are carried out without the output peaking spark gap switch, the very high voltage output signal has a duration approaching $5 \mu \mathrm{s}$, with multiple voltage inversions making the electrical stress conditions much more demanding than those 


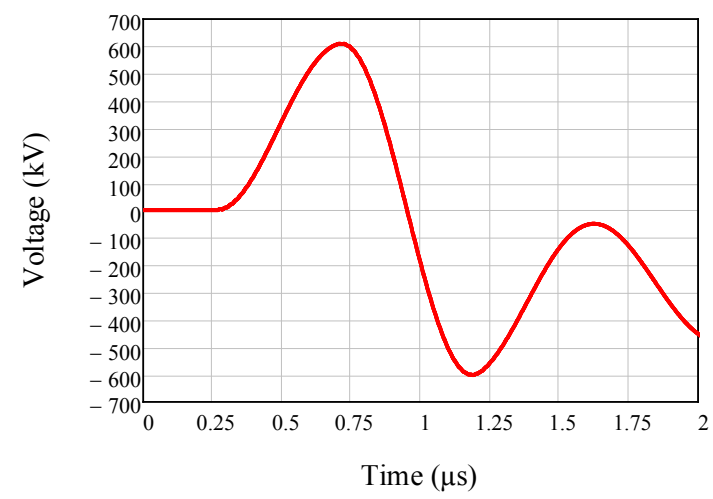

(a)

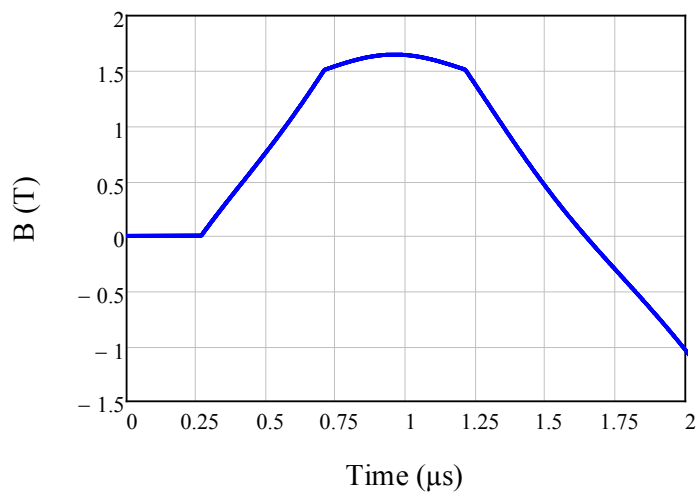

(b)

Figure 146: LTSpice results: (a) transformer output voltage; (b) magnetic flux density inside magnetic core

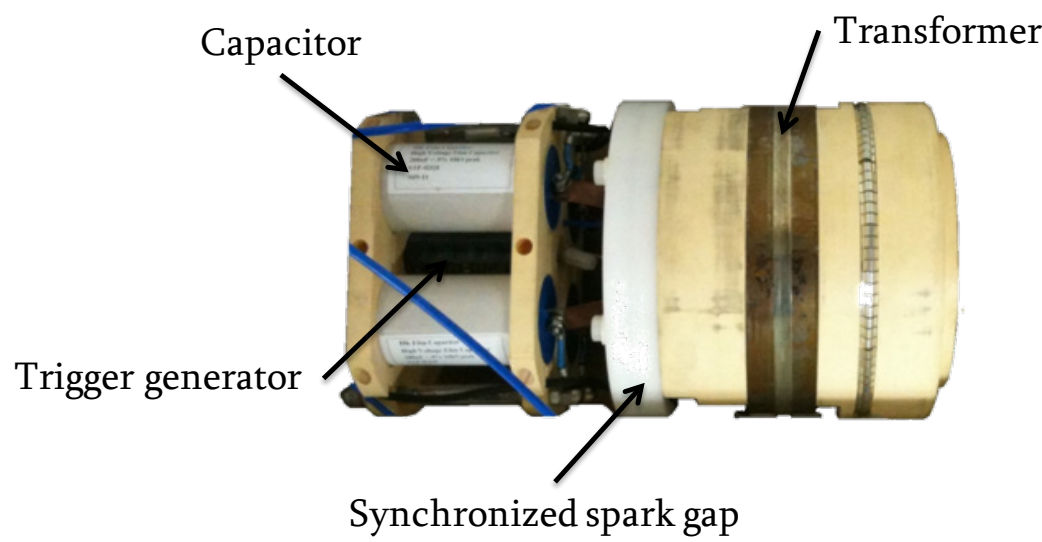

Figure 157: Ultra-compact arrangement of the pulsed transformer based generator

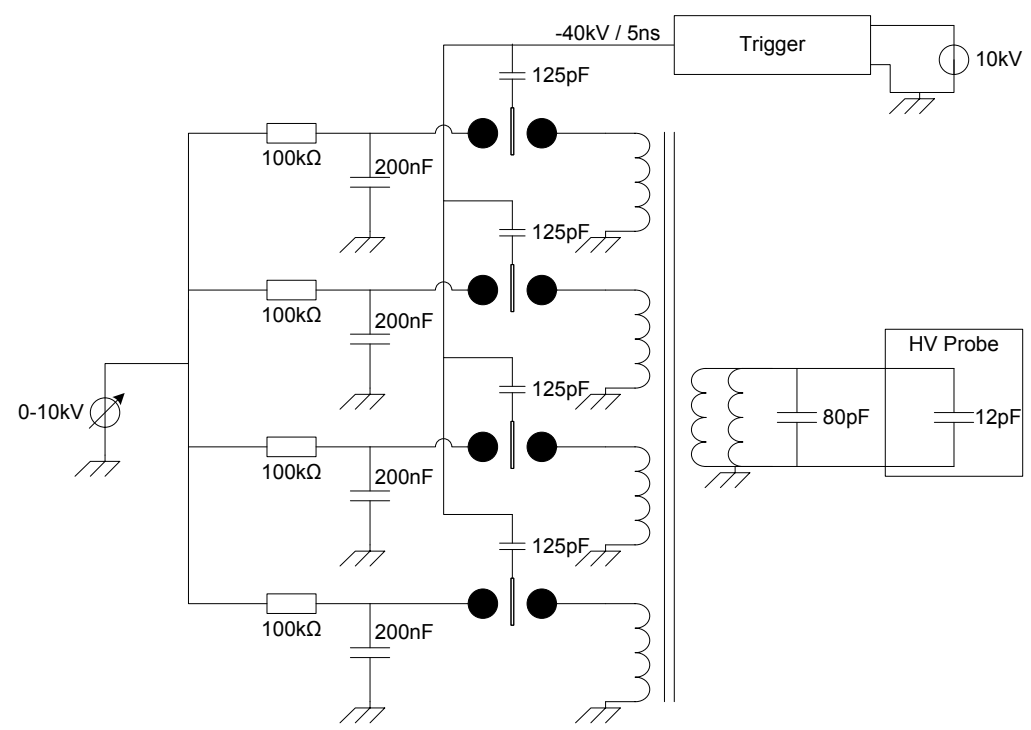

(a)

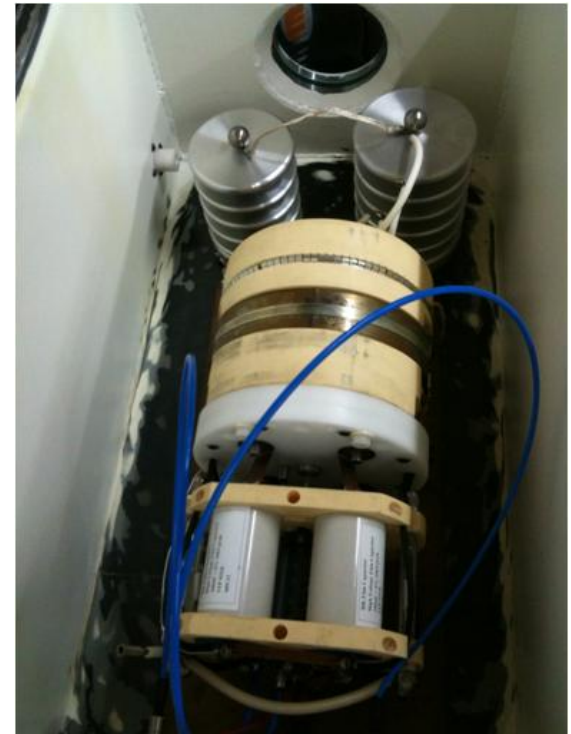

(b)

Figure 168: (a) Electrical scheme of the test and (b) photo of the real experimental arrangement without oil 


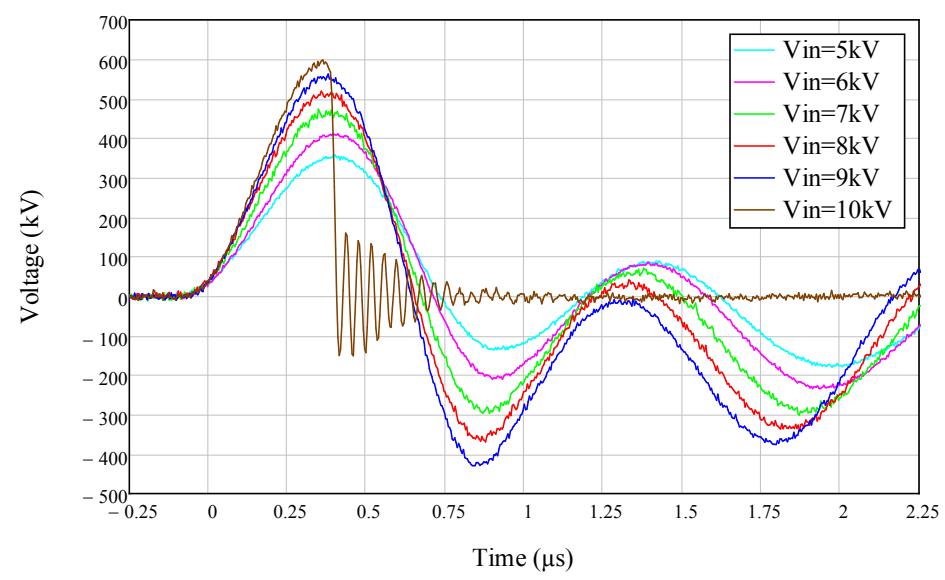

Figure 17: Time-variation of transformer output voltage for input voltages in the range $5 \mathrm{kV}$ to $10 \mathrm{kV}$

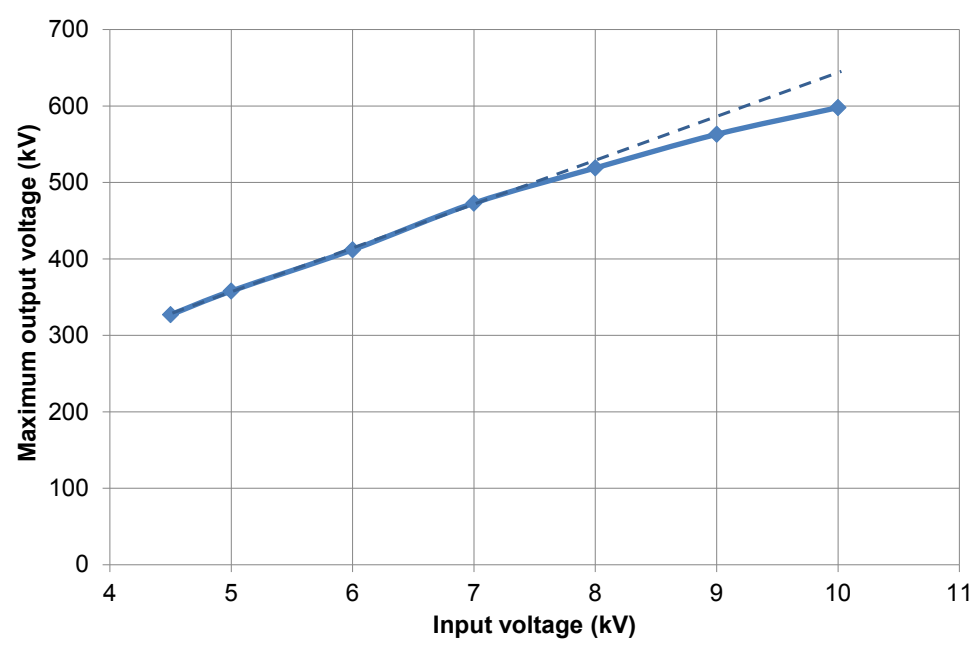

Figure 180: Variation of the transformer output peak voltages for an input voltage in the range $4.5 \mathrm{kV}$ to $10 \mathrm{kV}$

encountered during operation with the transformer based generator placed inside the MOUNA assembly. This issue required a very careful monitoring of the degassed oil.

\section{Results obtained in single-shot mode}

Fig. 19 presents the measured time history of the output voltage for input voltages with a constant rise time around $265 \mathrm{~ns}$ in the range between $5 \mathrm{kV}$ to $10 \mathrm{kV}$. At $0.6 \mathrm{MV}$, the transformer still operated normally but unfortunately an electrical breakdown was noticed inside the $80 \mathrm{pF}$ capacitor simulating the $\mathrm{C}_{\text {line }}$ capacitance. As shown in Fig. 20, the output voltage increases linearly as a function of the input voltage up to $0.5 \mathrm{MV}$. For higher voltages, as predicted by the LTSpice model, the magnetic core begins to saturate before the end of the energy transfer. It is possible, at least theoretically, to overcome this saturation by pre-magnetizing the magnetic circuit with a DC voltage of opposite polarity to the input voltage, in order to cover the entire amplitude of the hysteresis cycle of the magnetic material. To date this solution has not been tested, because it would at best increase the peak voltage by a few percentages, while adding a demanding complexity to the compact system.

\section{Results obtained in repetitive mode}

It is well-known that the high-intensity electric stress issue becomes much more demanding in a high PRF mode and therefore it was necessary to limit the time duration the dielectrics are stressed by performing the tests under conditions closer to those of the MOUNA prototype. In order to do this, a pressurized gas spark gap was installed to crowbar the output voltage impulse on a $50 \Omega$ resistor, when the output voltage impulse 


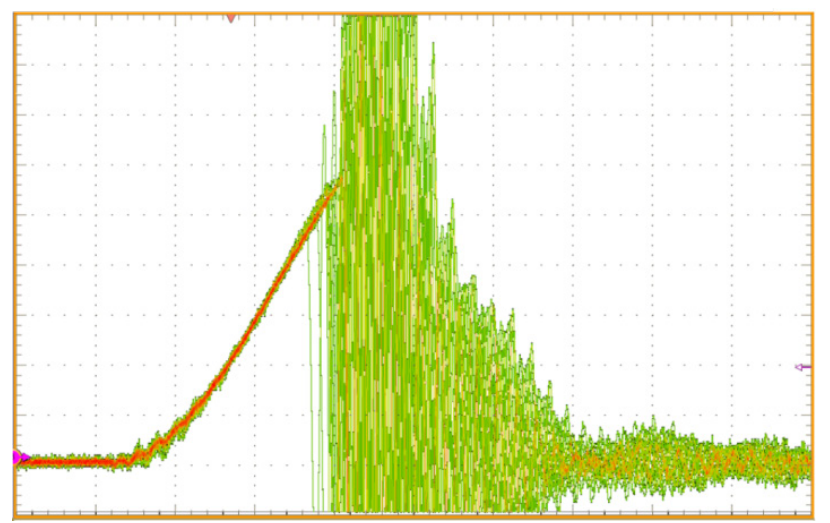

Figure 191: The record of a burst of 100 voltage impulses at a PRF of $20 \mathrm{~Hz}$ (vertical sensitivity $50 \mathrm{kV} /$ div; time interval $160 \mathrm{~ns} /$ div)

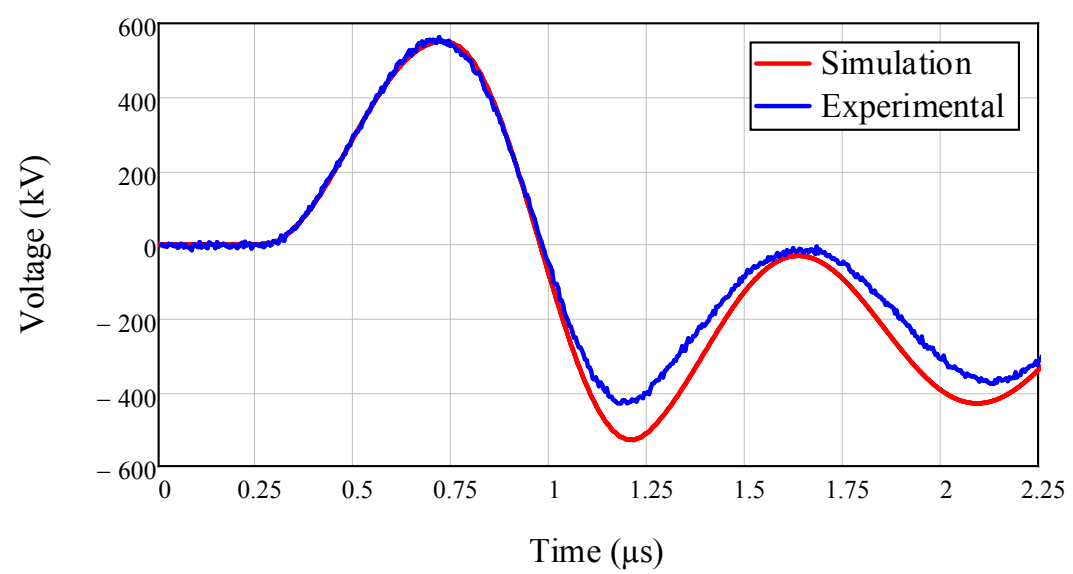

Figure 202: Typical pulsed transformer output voltages, for $9 \mathrm{kV}$ input, measured and simulated

reached a value close to its peak. It is important to note that the crowbar also eliminates the dangerous polarity reversal. Fig. 21 presents data obtained from a burst of 100 pulses at a PRF of $20 \mathrm{~Hz}$. After crowbarring, the measurement is unfortunately not very accurate, because the frequency of the resulting oscillations is higher than the $50 \mathrm{MHz}$ bandwidth limit of the $0.6 \mathrm{MV}$ probe.

The reproducibility of the output pulses generated by the transformer is very good, showing no sign of magnetic core saturation. The PRF was limited by the power of the capacitor chargers, but the tests nevertheless allowed assessing the reliability of the oil degassing, an important issue related to maintenance operation of the overall MOUNA prototype.

\section{Comparison between experimental data and thoretical predictions}

Fig. 22 compares the experimental results for an initial charging voltage of $9 \mathrm{kV}$ with predictions made using the LTspice modelling. The small differences noticed after $1 \mu \mathrm{s}$ are due to the imperfect modelling of the magnetic core losses, but this issue is not important for the present project as it happens after the peak voltage is reached and when most of the energy is already transferred to the antenna. The peak output voltage impulse is $560 \mathrm{kV}$, with a rise time of $265 \mathrm{~ns}$ and a time-to-peak of $440 \mathrm{~ns}$, well inside the values of parameters required by the MOUNA project.

\section{Summary}

The paper presented the study, characterization and the practical implementation of a high-voltage, magnetic core, resonant pulsed transformer. For final testing operations, a $0.6 \mathrm{MV}$ voltage probe and a capacitive load were also necessary to be designed, manufactured and calibrated which in itself they were the subject of an 
extensive supplementary study. The pulsed transformer, which occupies an overall volume of less than 3.5 litres, generates voltage impulses with a peak up to $0.6 \mathrm{MV}$ amplitude with a rise time of $265 \mathrm{~ns}$ on a load of $92 \mathrm{pF}$ (the capacitive load has $80 \mathrm{pF}$, with a supplementary $12 \mathrm{pF}$ introduced by the high-voltage probe). Calculation of the various parasitic inductive and capacitive elements made possible the development of an LTspice model for the transformer and therefore to very accurately predict and control the most important experimental results.

Finally, a very important lesson for the community was learnt: the simple analytical estimates presented in this work can be trusted when designing magnetic core pulsed transformers with the consequence that complex numerical studies using expensive software like CST are not really required!

\section{ACKNOWLEDGMENTS}

This work was initiated and financially supported by the French Ministry for Defense (Direction Générale de l'Armement - contract $\mathrm{N}^{\circ}$ 07.34.027).

The authors gratefully acknowledge L. Caramelle, J-M. Duband, S. Roche and F. Girard from Hi Pulse Company for their dedicated work and the useful discussions along the research programme.

\section{Conflict of interest}

The authors confirm that this article content has no conflict of interest.

\section{References}

[1] D. Morton et al., "A 2MV, <300ps risetime, $100 \mathrm{~Hz}$ pulser for generation of microwaves », in Power Modulator and High Voltage Conference (IPMHVC), 2010 IEEE International, 2010, p. 361-364.

[2] V. I. Koshelev, V. V. Plisko, et K. N. Sukhushin, «Array Antenna for Directed Radiation of High-Power Ultra-wideband Pulses ", in Ultra-Wideband, Short Pulse Electromagnetics 9, F. Sabath, D. V. Giri, F. Rachidi, et A. Kaelin, Éd. Springer New York, 2010, p. 259-267.

[3] P. Delmote et B. Martin, "The GIMLI: A Compact High-Power UWB Radiation Source», in UltraWideband, Short Pulse Electromagnetics 9, F. Sabath, D. V. Giri, F. Rachidi, et A. Kaelin, Éd. Springer New York, 2010, p. 315-321.

[4] L. Pecastaing et al., «A 250KV-300PS-350HZ Marx generator as source for an UWB radiation system », in IEEE Pulsed Power Conference, 2009. PPC '09, 2009, p. 51-56.

[5] B. Cadilhon et al., "High Pulsed Power Sources for Broadband Radiation », IEEE Transactions on Plasma Science, vol. 38, n 10, p. 2593-2603, oct. 2010.

[6] C. E. Baum et al., «JOLT: A Highly Directive, Very Intensive, Impulse-Like Radiator », Sensor and Simulation Notes, $\mathrm{n}^{\circ} 480$, nov. 2003.

[7] Y. Amal et al., «A tesla transformer and a coaxial peaking switch as a UWB pulse source », Acta Physica Polonica A, vol. 115, nº 6, p. 1115-1117, 2009.

[8] K. D. Hong et S. W. Braidwood, «Resonant antenna-source system for generation of high-power wideband pulses », IEEE Transactions on Plasma Science, vol. 30, n 5, p. 1705-1711, oct. 2002.

[9] W. J. Carey et al., " Autonomous RF Radiation Package for Various Applications », in 2005 IEEE Pulsed Power Conference, 2005, p. 218-221.

[10]P. Sarkar, S. W. Braidwood, I. Smith, B. M. Novac, R. . Miller, et R. M. Craven, «A Compact BatteryPowered Half-Megavolt Transformer System for EMP Generation », IEEE Transactions on Plasma Science, vol. 34, n ${ }^{\circ}$ 5, p. 1832-1837, oct. 2006.

[11]R. Pecquois, L. Pécastaing, M. Rivaletto, A. S. De Ferron, et R. Vézinet, «MOUNA: An autonomous, compact, high-power, and wideband electromagnetic source based on a novel resonant pulsed transformer », IEEE Transactions on Plasma Science, vol. 40, n 5 PART 2, p. 1407-1415, 2012.

[12]« LTSpice software ». [En ligne]. Disponible sur: http://www.linear.com/designtools/software/. [Consulté le: 31-janv-2017]. 
[13]M. Denicolai, « Optimal performance for Tesla transformers », Review of Scientific Instruments, vol. 73, $\mathrm{n}^{\circ}$ 9, p. 3332-3336, sept. 2002.

[14]« CST Microwave Studio ». [En ligne]. Disponible sur: https://www.cst.com/products/cstmws. [Consulté le: 31-janv-2017].

[15]R. Pecquois et al., « An autonomous very compact pulsed power device based on synchronized spark gaps arrangement and an innovative resonant transformer ", in 2010 3rd IEEE Euro-Asian Pulsed Power Conference (EAPPC), Jeju Island, Korea, 2010.

[16]D. Bortis, G. Ortiz, J. W. Kolar, et J. Biela, «Design procedure for compact pulse transformers with rectangular pulse shape and fast rise times », IEEE Transactions on Dielectrics and Electrical Insulation, vol. 18, no 4, p. 1171-1180, 2011.

[17]«Mobilect 39 oil», Mobil Electrical insulating oils. $[$ En ligne]. Disponible sur: http://www.mobil.com/UK-English/Lubes/PDS/GLXXENINDMOMobilect_39.aspx. [Consulté le: 18févr-2016].

[18]K. E. Nielsen et al., «Atlas transmission line breakdown analysis », in Pulsed Power Conference, 1999. Digest of Technical Papers. 12th IEEE International, 1999, vol. 1, p. 381-384 vol.1.

[19]R. Pecquois et al., "An oil peaking switch to drive a dipole antenna for wideband applications », in 2011 IEEE International Conference on Dielectric Liquids (ICDL), 2011, p. 1-4.

[20]«Metglas 2605SA1», Metglas ${ }^{\circledR}$ Magnetic Alloy. $[$ En ligne]. Disponible sur: http://www.metglas.com/products/magnetic_materials/2605sa1.asp. [Consulté le: 18-févr-2016].

[21]C. P. Steinmetz, « On the law of hysteresis », Proceedings of the IEEE, vol. 72, $\mathrm{n}^{\circ}$ 2, p. 197-221, févr. 1984.

[22]Y. Du, S. Baek, S. Bhattacharya, et A. Q. Huang, « High-voltage high-frequency transformer design for a $7.2 \mathrm{kV}$ to $120 \mathrm{~V} / 240 \mathrm{~V} 20 \mathrm{kVA}$ solid state transformer », in IECON 2010 - 36th Annual Conference on IEEE Industrial Electronics Society, 2010, p. 493-498.

[23]I. Hernandez, F. de Leon, et P. Gomez, «Design Formulas for the Leakage Inductance of Toroidal Distribution Transformers », IEEE Transactions on Power Delivery, vol. 26, n 4, p. 2197-2204, oct. 2011.

[24]Jacob Millman \& Herbert Taub, Pulse Digital \& Switching Waveforms, $1965^{\mathrm{e}}$ éd. McGraw-Hill.

[25]« CST EM Studio ». [En ligne]. Disponible sur: https://www.cst.com/products/cstems. [Consulté le: 31janv-2017].

[26]W. T. McLyman, Transformer and Inductor Design Handbook, Fourth Edition. Boca Raton FL: CRC Press, 2011.

[27]R. Pecquois et al., «Simple and compact capacitive voltage probe for measuring voltage impulses up to $0.5 \mathrm{MV} »$, Review of Scientific Instruments, vol. 83, $\mathrm{n}^{\mathrm{0}} 3,2012$.

[28]J. H. Chan, A. Vladimirescu, X. C. Gao, P. Liebmann, et J. Valainis, « Nonlinear transformer model for circuit simulation », IEEE Transactions on Computer-Aided Design of Integrated Circuits and Systems, vol. 10, nº 4, p. 476-482, avr. 1991. 